\title{
Sensores Electroquímicos em Hidroponia
}

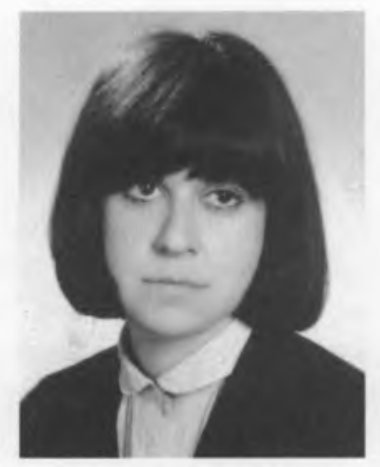

M. ${ }^{3}$ ManuelP.M. Neto

Licenciou-se em Química na Faculdade de Ciências de Lisboa, em 1974.

Em 1975 iniciou a actividade científica no Centro de Electroquímica e Cinética da Universidade de Lisboa (INIC), onde é responsável por um projecto no âmbito da Electroquímica, na linha de acção n. $\% 4$ do CECUL.

Em 1976 foi contratada como Assistente do Instituto Superior de Agronomia, onde é Professora Auxiliar desde 1987.

De 1981 a 1983 realizou um estágio no Imperial College no grupo do Professor John Albery.

Em 1987, doutorou-se em Química Física na Faculdade de Ciências de Lisboa.

Participa, desde 1988, num projecto subsidiado pela JNICT, realizado em colaboração com o Jardim-Museu Agrícola Tropical, relacionado com o desenvolvimento e automatização de sensores electroquímicos para culturas hidropónicas com técnica de filme nutriente.

\section{Introdução}

Os temas relacionados com sensores electroquímicos são hoje frequentemente abordados em variadíssimos ramos da Ciência e da Tecnologia, não só no que respeita à sua efectiva utilização como também por constituirem objecto de investigação em inúmeros projectos que se encontram em fase de desenvolvimento na comunidade científica.

Se por um lado tal se deve à necessidade cada vez mais urgente de determinar, em diferentes meios e situações, concentrações muito baixas de certas espécies químicas, deve-se também seguramente por outro aos progressos em flecha que se têm vindo a conseguir nos últimos anos em áreas como a electrónica e as ciências de computação.

A justificação da preferência dos sensores electroquímicos, relativamente a outros, reside obviamente no facto de oferecerem vantagens relevantes. Essas vantagens estão principalmente relacionadas com factores de ordem económica, facilidade de utilização e manutenção, possibilidade de automatização, e, acima de tudo, rapidez na resposta com elevada sensibilidade e reprodutibilidade.

Uma listagem significativa de sensores utilizados em diferentes domínios seria demasiado extensa, não correspondendo sequer ao objectivo deste artigo. A título de exemplo, pode contudo ser feita referência a um sensor de uso tão vulgarizado como o eléctrodo de $\mathrm{pH}$ ou a outros menos conhecidos, como o eléctrodo de oxigénio e o de glucose. Das aplicações já em curso destes dois sensores, algumas em regime experimental, exemplifacam-se aqui duas, importantes a nível clínico - a determinação da concentração de oxigénio na circulação sanguínea em recém-nascidos e o controlo do metabolismo do açúcar em doentes diabéticos. Também em áreas como a Bioquímica, a Tecnologia dos Produtos Alimentares, as Ciências do Ambiente e outras, os sensores electroquímicos têm vindo a desempenhar papel relevante. A determinação dos chamados oligoelementos, essenciais aos mecanismos vitais, nos seres vivos e na sua alimentação, assim como o controlo da poluição ambiental no sentido de prevenir o aparecimento de problemas derivados da toxicidade de determinadas substâncias, podem ser levados a efeito em muitos casos por via electroanalítica. As Ciências Agrárias constituem um outro domínio de aplicação. No caso particular da hidroponia, o emprego de sensores electroquímicos afigura-se como a via mais apropriada para controlar, em contínuo, os níveis de nutrientes presentes no meio onde as plantas se desenvolvem.

\section{Sobre a hidroponia}

Cabe aqui falar um pouco sobre a hidroponia e sua história, pois trata-se de uma palavra ainda pouco familiar na linguagem corrente.

${ }^{3}$ Professora Auxiliar da Seç̧ão de Química do Instituto Superior de Agronomia. CECUL, Calçada Bento da Rocha Cabral, 14, 1200 Lisboa. 
Foi em 1930 que o termo de origem grega hidroponia (hydro+ponus), sistema de cultura de plantas em água, foi introduzido por Gericke [1]. Porém, são já marcos históricos da sua prática, na Antiguidade, os jardins suspensos da Babilónia e os jardins flutuantes dos astecas e dos chineses. $\mathrm{O}$ primeiro trabalho de carácter científico em que se demonstrou ser a água o agente que veicula a absorção de sais minerais realizada pelas plantas data de 1600 . Até meados do século passado sabia-se que o desenvolvimento das plantas podia decorrer normalmente num meio de cultura inerte desde que impregnado com uma solução aquosa contendo todos os elementos que lhes são essenciais. Em 1860, dois cientistas germânicos, Sachs e Kmop, eliminaram o suporte sólido, mantendo as culturas apenas em solução. Esta prática, que se designa por «nutricultura», ainda hoje é utilizada em estudos de Fisiologia e Nutrição Vegetais.

Tais estudos permitiram concluir que há um conjunto de elementos essenciais às plantas - os chamados macronutrientes, elementos de que a planta necessita em quantidades apreciáveis, e os micronutrientes indispensáveis, mas tolerados apenas em quantidades diminutas.

A hipótese de comercialização de produtos cultivados por técnica hidropónica só começou a ser encarada após trabalhos desenvolvidos por Gericke na Universidade da Califórnia, onde, no início dos anos 30, funcionaram pela primeira vez estufas com culturas hidropónicas de batata, beterraba, alface e tomate. Foi graças à hidroponia que, durante a Segunda Guerra Mundial, se tornou possível garantir o abastecimento de vegetais frescos às tropas americanas estacionadas nas ilhas do Pacífico de solo não-arável. A partir daí a técnica passou a ter aceitação por parte de um número considerável de estuficultores encontrando-se actualmente implantada em diversos países como Itália, Reino Unido, Espanha, França, Holanda, Israel e outros, incluindo, mais recentemente, Portugal.

Comparando com a cultura em solo, podem-se tirar já algumas conclusões acerca das vantagens inerentes ao sistema. As mais significativas resumem-se à possibilidade de utilização de zonas áridas, ao encurtamento do ciclo evolutivo das plantas, o que traz como consequências um melhor aproveitamento do espaço disponível e uma garantia de aprovisionamento mais regular dos produtos ao longo de todo o ano [2], e a adição de forma controlada de nutrientes à solução nutritiva.

Do consumo de nutrientes por parte da planta resulta um abaixamento da sua concentração na vizinhança da raiz. As concentrações apropriadas terão de ser repostas, já que o simples processo de transferência de massa por difusão se torna demasiado lento e ineficaz.

Este problema pode ser minorado pela utilização da técnica de filme nutritivo (NFT), introduzida por Allen Cooper [3] em 1966 no Glasshouse Crops Research Institute (GCRI), em Littlehampton. Em NFT, as raízes encontram-se imersas numa corrente de solução contendo todos os nutrientes necessários ao crescimento das plantas, nas concentrações adequadas. Essa solução circula continuamente em reservatórios de baixa profundidade, proporcionando assim uma distribuição uniforme de nutrientes às plantas. Na Figura 1 apresenta-se o esquema de uma instalação típica hidropónica, com NFT.

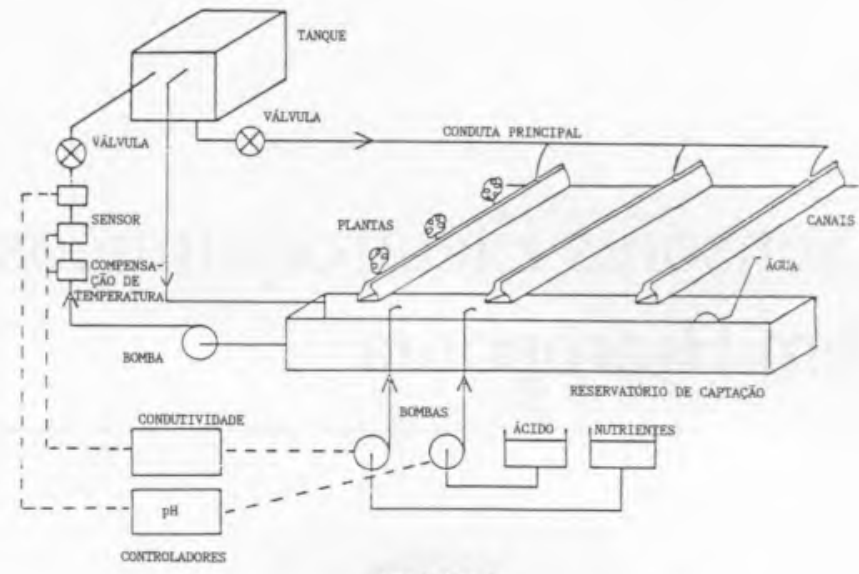

FIGURA 1

Esquema dumainstalaçâo hidropónica(NFT)

Da composição de uma solução nutritiva fazem parte os macronutrientes (cálcio, potássio, azoto, fósforo, magnésio, sódio e cloro) e os micronutrientes (ferro, manganês, boro, cobre, zinco e molibdénio), estes em concentrações bastante baixas que não podem exceder limites bem definidos, o que poria em risco o bom desenvolvimento da cultura, quer por excesso (sintomas de toxicidade), quer por defeito (carências alimentares). Na Tabela 1 encontram-se indicadas as concentrações aconselhadas por Cooper para cultura NFT de tomate [4].

TABELA 1

Composiçầo duma soluçāo nutritiva típica usada no início de cultura NFT detomate

\begin{tabular}{|l|ll|}
\hline \multirow{2}{*}{ Composto } & \multicolumn{2}{|c|}{ Concentração } \\
& $\mathrm{g} \mathrm{dm}^{-3}$ & $\mathrm{~mol} \mathrm{dm}^{-3}$ \\
\hline $\mathrm{Ca}\left(\mathrm{NO}_{3}\right)_{2} \cdot 4 \mathrm{H}_{2} \mathrm{O}$ & 0,9898 & $4,2 \times 10^{-3}$ \\
$\mathrm{KNO}_{3}$ & 0,6568 & $6,5 \times 10^{-3}$ \\
$\mathrm{KH}_{2} \mathrm{PO}_{4}$ & 0,2722 & $2,0 \times 10^{-3}$ \\
$\mathrm{MgSO}_{4}$ & 0,3469 & $2,9 \times 10^{-3}$ \\
$\mathrm{FeNaEDTA}$ & 0,0368 & $1,0 \times 10^{-4}$ \\
$\mathrm{MnSO}_{4} \cdot 4 \mathrm{H}_{2} \mathrm{O}$ & 0,0089 & $4,0 \times 10^{-5}$ \\
$\mathrm{H}_{3} \mathrm{BO}_{3}$ & 0,0018 & $2,9 \times 10^{-5}$ \\
$\mathrm{CuSO}_{4} \cdot 5 \mathrm{H}_{2} \mathrm{O}$ & $2,5 \times 10^{-4}$ & $1,0 \times 10^{-6}$ \\
$\mathrm{ZnSO}_{4} \cdot 7 \mathrm{H}_{2} \mathrm{O}$ & $2,9 \times 10^{-4}$ & $1,0 \times 10^{-6}$ \\
$\left(\mathrm{NH}_{4}\right) \mathrm{Mo}_{7} \mathrm{O}_{24} \cdot 4 \mathrm{H}_{2} \mathrm{O}$ & $3,7 \times 10^{-4}$ & $3,0 \times 10^{-7}$ \\
\hline
\end{tabular}

Níquel é outra espécie metálica que carece de quantificação cautelosa em meio nutritivo. Não fazendo parte da composição da solução, aparece, contudo, muito frequentemente como seu contaminante, devido à corrosão de certo tipo de resistências eléctricas vulgarmente utilizadas na estação fria para o aquecimento das soluções. A absorção daquele elemento por parte da planta pode torná-la nociva para a dieta animal, uma vez que a espécie tem efeitos carcinogénicos já comprovados $[5,6]$.

Importante é ainda o controlo do índice de matéria orgânica presente nas soluções, cujo aumento brusco é um indicativo de morte prematura das raízes, problema que afecta com grande incidência este tipo de cultura [7].

Finalmente, é também de referir a necessidade premente de controlar o pH das soluçōes, cujo valor deverá situar-se na 
região ligieramente ácida, ou seja, no intervalo entre 5,5 e 6,5 . Valores abaixo de 5,5 tornar-se-iam prejudiciais para a vitalidade das plantas e para o bom estado das bombas de circulação; valores acima de 6,5 contribuiriam para um abaixamento de concentração de certos nutrientes, por serem favorecidos mecanismos de reacções de precipitação e de complexação.

\section{Utilização dos sensores}

É, pois, evidente que o controlo de espécies químicas em hidroponia é um problema que merece ser cuidadosamente tratado e solucionado.

Há poucos anos atrás esse controlo resumia-se apenas a medidas de $\mathrm{pH}$ e de condutividade e, eventualmente à determinação de alguns nutrientes por espectroscopia de absorção atómica [8], o que forçosamente implicava a recolha periódica de amostras. Este procedimento foi-se revelando ineficaz e inadequado, tendo-se constatado que era urgente a criação de um sistema de análise em linha, mais completo e sofisticado. É importante dispor de um conjunto de sensores de baixo custo, em linha de fluxo, que permita um conhecimento contínuo e rigoroso da composição da solução e passível de automatização. Tais condições são, na generalidade, satisfeitas por sensores electroquímicos, considerados neste caso o método de eleição.

Assim, na última década, grupos de investigadores electroquímicos, em colaboração com estações hidropónicas experimentais e comerciais, têm-se dedicado ao desenvolvimento de sensores, alguns dos quais já em plena fase de utilização em estufas.

Além de permitir fornecer ás plantas as quantidades correctas de nutrientes durante o seu ciclo evolutivo, e optimizar as condições do meio de cultura, a informação analítica que os sensores permitem recolher constitui, sem dúvida, uma contribuição valiosa para a realização de estudos de Fisiologia e de Nutrição Vegetal.

Os macronutrientes são, no geral, doseados por via potenciométrica com eléctrodos selectivos de iões. A sua resposta pode ser afectada por oscilações de força iónica e por efeitos de interferência de outras espécies presentes, o que normalmente se traduz em instabilidade [9]. No entanto, desenvolvendo relações teóricas e empíricas entre estes efeitos é possível programar um microprocessador de molde a interpretar a resposta dos diferentes eléctrodos em termos de concentrações.

Actualmente, dispõe-se já de um sistema analisador, controlado por microprocessador [10], onde os eléctrodos se encontram dispostos em linha numa célula de fluxo, incluindo o eléctrodo de $\mathrm{pH}$. $\mathrm{O}$ analisador é completamente automático na realização de várias operações - calibração, amostragem de solução, medição de f.e.m. e eliminação de interferências - e os resultados são apresentados em termos de concentrações.

O doseamento dos micronutrientes bem como a detecção de matéria orgânica têm sido levados a cabo com métodos amperométricos [11-15], usando novos sensores, com hidrodinâmica controlada, especialmente desenvolvidos para esse fim, sempre com base no eléctrodo «wall-jet» [16]. O eléctrodo «wall-jet», de disco ou de anel e disco, é considerado, de entre os eléctrodos de fácil inserção em linha de fluxo, o mais adequado para fins analíticos. Comparando-o com o eléctrodo tubular, por exemplo, destacam-se vantagens como maior sensibilidade, manutenção mais acessível e hidrodinâmica bem definida. As suas potencialidades do ponto de vista analítico são ainda favorecidas pela possibilidade de acoplamento de um reactor do tipo «eléctrodo de leito empacotado", colocado na linha de fluxo em posição imediatamente anterior à formação do jacto, não introduzindo, assim, qualquer perturbação na hidrodinâmica do sistema. O reactor pode ser aproveitado ou para produzir um reagente pouco estável cuja presença seja necessária no compartimento de reacção da célula wall-jet [11], ou para reconstituir uma superfície fresca de eléctrodo [17] ou mesmo para servir de suporte a reacções enzimáticas (eléctrodos de enzimas) [18]. A célula wall-jet associada ou não ao eléctrodo de leito empacotado estão representados na Figura 2.
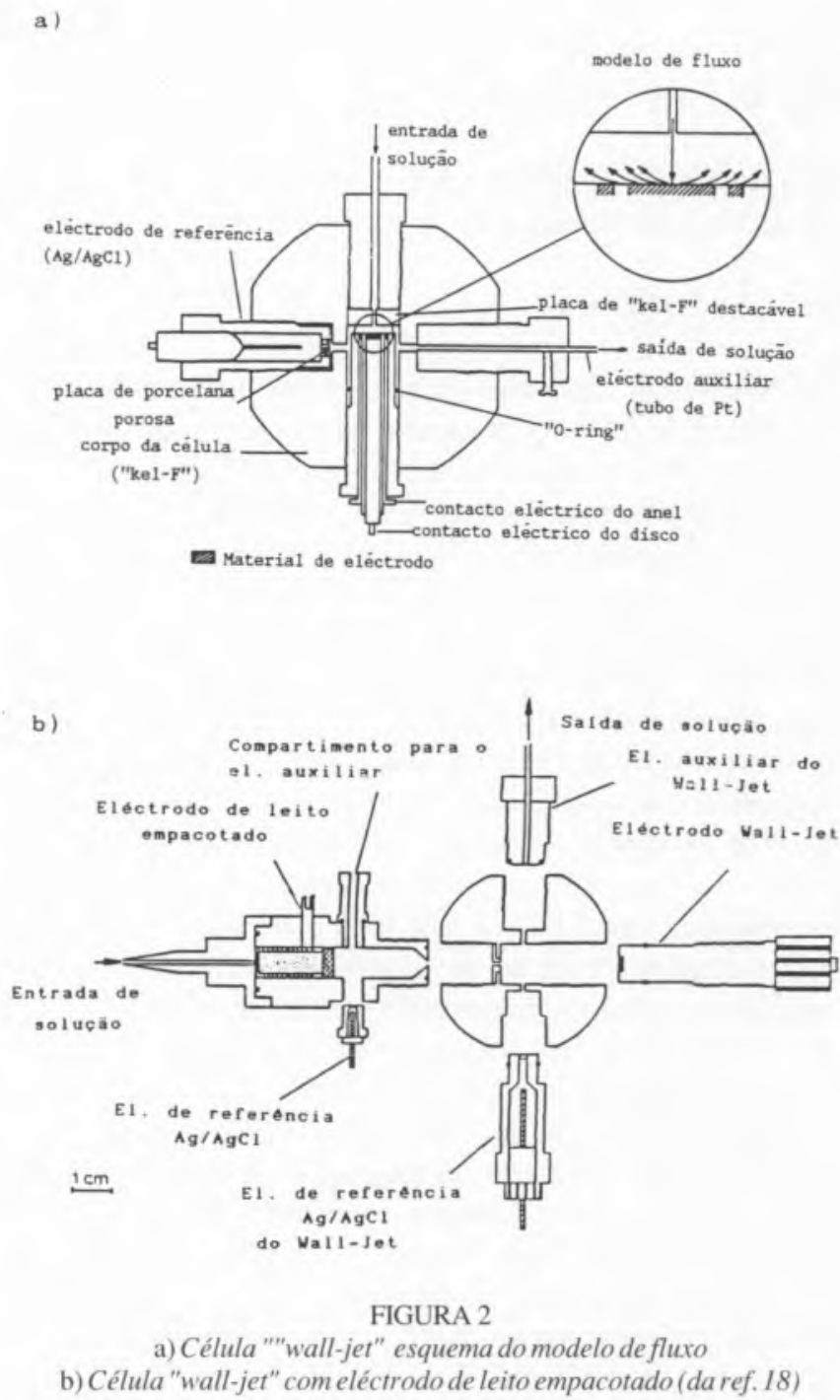

No wall-jet a solução é forçada, em jacto de cerca de $0,1 \mathrm{~mm}$ de diâmetro, a incidir perpendicularmente num pequeno disco (cerca de $3 \mathrm{~mm}$ de diâmetro), ou num eléctrodo duplo disco-anel, construídos no material de eléctrodo escolhido. A corrente limite, $i_{D . L}$, observada no eléctrodo está directa- 
mente relacionada com a concentração, $\mathrm{c}_{\infty}$, e outros parâmetros da expressão [16]:

$\mathrm{i}_{\mathrm{D}, \mathrm{L}}=1,38 \mathrm{nF} \mathrm{D}^{2 / 3} \mathrm{v}^{-5 / 12} \mathrm{~V}_{\mathrm{f}}^{3 / 4} \mathrm{a}^{-1 / 2} \mathrm{c}_{\infty} \mathrm{r}^{3 / 4}$

onde D é o coeficiente de difusão da espécie electroactiva, $v$ a viscosidade cinemática da solução, $V_{\mathrm{f}}$ a velocidade de escoamento, a o diâmetro do jacto e $r_{1}$ o raio do eléctrodo de disco.

Quando a concentração da espécie a determinar é suficientemente elevada (até cerca de $10^{-4} \mathrm{~mol} \mathrm{dm}^{-3}$ ) torna-se viável proceder ao seu doseamento por amperometria a potencial constante no eléctrodo de disco. Foi este o método adoptado no desenvolvimento de um sensor para o controlo do ferro total nas soluções nutritivas [11].

Num pre-electrolisador de leito empacotado em carbono vítreo reticulado, contendo um compartimento com fragmentos de platina platinizada, submetido ao valor conveninente de potencial, dão-se as reacções:

$\mathrm{Fe}(\mathrm{III})+\mathrm{e} \rightarrow \mathrm{Fe}(\mathrm{II})$

$\mathrm{O}_{2}+4 \mathrm{e}+4 \mathrm{H}^{+}(\mathrm{aq}) \rightarrow 2 \mathrm{H}_{2} \mathrm{O}$

A concentração de ferro total é, então, determinada no walljet de disco de platina onde se dá a oxidação:

$\mathrm{Fe}(\mathrm{II}) \rightarrow \mathrm{Fe}(\mathrm{III})+\mathrm{e}$

Por se tratar dum nutriente de extraordinária importância, foi proposto [17], para o ião nitrato, um sensor amperométrico em alternativa ao sensor potenciométrico. Uma vez que o material de eléctrodo indicado para a detecção de nitrato é o cobre, mas sendo este muito susceptível a fenómenos de envenenamento, optou-se pela inserção de um eléctrodo de leito empacotado em cobre de cuja redução electroquímica resulta ião cúprico, usado na electrodeposição duma camada fresca deste metal num eléctrodo wall-jet de disco de platina. A concentração de nitrato é, então, determinada amperometricamente neste eléctrodo, a potencial constante.

Quando as espécies ocorrem em concentrações vestigiais, como é o caso, por exemplo, do cobre, zinco, manganês, molibdénio, níquel, há que recorrer a métodos de preconcentração electroquímica no desenvolvimento de sensores que satisfaçam os limites de detecção pretendidos (Tabela 1) [1]. A voltametria de redissolução, quer anódica quer catódica, tem sido a técnica adoptada [12 - 15].

Fundamentalmente, resume-se a duas etapas - electrodeposição prévia no eléctrodo do material a quantificar, seguida da sua redissolução electroquímica a potencial controlado. $\mathrm{O}$ problema principal deste método consiste na forma como eliminar a componente não-faradaica de que vem afectada a corrente de redissolução medida.

A via que se tem seguido para resolver este problema do desenvolvimento de sensores para alguns micronutrientes consiste na aplicação da voltametria de redissolução com recolha a eléctrodos wall-jet de disco e anel [19]. Realiza-se a electrodeposição das espécies a analisar no disco, que é depois submetido a saltos de potencial para se dar a redissolução. Durante este passo o anel é mantido a um potencial tal que todas as espécies redissolvidas que o atingem, por difusão convectiva, se depositam. Sabendo o valor da eficiência de recolha do eléctrodo, ou seja, a fracção da espécie gerada no disco que pode ser detectada no anel, e registando os integrais dos transientes de corrente de anel, é possível determinar a concentração das espécies.

Seguindo este procedimento, desenvolveram-se já os seguintes sensores, para o controlo de micronutrientes em hidroponia:

- eléctrodo de filme de mercúrio electrodepositado in situ sobre carbono vítreo para a determinação simultânea de cobre, zinco e manganês, por voltametria de redissolução anódica [12-14];

- eléctrodos em carbono vítreo e em platina, para determinação de manganês, por voltametria de redissolução catódica do dióxido de manganês [12 - 15];

- eléctrodo em platina para a determinação de níquel, por voltametria de redissolução anódica $[13,14]$.

Um sensor para molibdénio encontra-se já em fase adiantada de desenvolvimento, utilizando voltametria de redissolução anódica, com eléctrodo de disco de carbono vítreo com filme de mercúrio. O passo de redissolução é, neste caso, levado a efeito mediante a aplicação de onda quadrada ao eléctrodo, o que reduz também significativamente a componente nãofaradaica da corrente.

Para a detecção de matéria orgânica no meio nutritivo foi proposto um autotitulador $[13,20]$, baseado na técnica de microtitulação na camada de difusão do eléctrodo wall-jet de disco e anel [21].

Geralmente os compostos orgânicos não são electroactivos, excepto a potenciais extraordinariamente elevados. Contudo, as suas moléculas apresentam centros electrofílicos muito reactivos que podem ser titulados, por exemplo, com hipobromito, a pH 9,2. Gerando no disco ião $\mathrm{BrO}^{-}$que reaja com as espécies orgânicas, $\mathrm{X}$, em solução, uma fracção do hipobromito remanescente é detectada no anel. O esquema do método é o seguinte:

No eléctrodo de disco: $\mathrm{Br}+2 \mathrm{OH}^{-} \rightarrow \mathrm{BrO}^{-}+\mathrm{H}_{2} \mathrm{O}+2 \mathrm{e}$

$\mathrm{Na}$ solução: $\mathrm{BrO}^{-}+\mathrm{X} \rightarrow$ produtos

No eléctrodo de anel: $\mathrm{BrO}^{-}+\mathrm{H}_{2} \mathrm{O}+2 \mathrm{e} \rightarrow \mathrm{Br}^{-}+2 \mathrm{OH}^{-}$

Aplicando este método construiu-se um autotitulador que produz bons resultados na detecção do índice de matéria orgânica presente no meio.

A automatização dos sensores acima descritos tem sido objecto de estudo, nos últimos anos, de projectos que congregam o trabalho de investigadores das Universidades de Londres, Lisboa e Coimbra.

Dispõe-se já de uma interface com microprocessador programável, construída na Unidade de Microprocessadores do Departamento de Química do Imperial College of Science and Technology, Universidade de Londres. O referido equipamento, que actualmente se encontra a ser experimentado no CECUL, está em vias de instalação no Jardim-Museu Agrícola Tropical em Lisboa, onde existe uma estufa com cultura NFT de tomateiro e feijoeiro; o objectivo da sua utilização consiste no controlo automático dos nutrientes. O sistema analisador, que neste caso se aplica ao nível dum meio de cultura de plantas, tem, no entanto, potencialidades 
para ser usado noutras matrizes aquosas, mediante a introdução de ajustamentos adequados.

\section{Referências}

[1] W.F. Gericke, The Complete Guide to Soilless Gardening, Putnam, London, 1940.

[2] R.C.R. Santos Victor, A Cor do Substrato e o Número de Regas na Cultura Hidropónica, IICT, Lisboa, 1986.

[3] A. Cooper, The ABC of NFT, Grower Books, London, 1979.

[4] A. Cooper, Commercial Applications of NFT, Grower Books, London, 1982.

[5] F.W. Sunderman, Jr., Pure Appl.Chem., 1980, 52, 527.

[6] H. Braun e M. Metzger, Fresenius Z. Anal.Chem., 1984, 318, 321.

[7] M.L. Daughtrey e P.A. Schippers, Acta Horticulturae, 1980, 98, 283.

[8] R.O. Scott, R.L. Mitchell, D. Purves e R.C. Voss, Spectrochemical Methods for the Analysis of Soils Plants and Other Agricultural Materials, The Macauley Institute for Soil Research, Bull. 2, 1971.

[9] G.S. Weaving e A. Hunter, An Assesment of Ion Selective Electrodes for Monitoring Nutrient Culture Systems, National Institute of Agricultural Engineering Divisional Note 1143, 1982.
[10] L.R. Svanberg, Ph.D.Thesis, Imperial College, London, 1984.

[11] W.J. Albery e M.M.P.M. Neto, Portugaliae Electrochim. Acta, 1985, 3, 67.

[12] C.M.A. Brett e M.M.P.M. Neto, J. Chem. Soc., Faraday Trans. 1, $1986,82,1071$.

[13] M.M.P.M. Neto, Tese de Doutoramento, F.C.L., Lisboa, 1987.

[14] C.M.A. Brett e M.M.P.M. Neto, Portugaliae Electrochim. Acta, 1987, 5, 305.

[15] C.M.A. Brett e M.M.P.M. Neto, J. Electroanal. Chem., 1989, 258, 345. [16] W.J. Albery e C.M.A. Brett,J.Electroanal.Chem., 1983, 148, 201.

[17] W.J. Albery, B.G.D. Haggett, C.P. Jones, M.J. Pritchard e L.R. Svanberg, J.Electroanal.Chem., 1985, 188, 257.

[18] W.J. Albery, P.N. Bartlett, A.E.G. Cass, D.H. Craston e B.G.D. Haggett, J.Chem. Soc., Faraday Trans. 1, 1986, 82, 1033.

[19] W.J. Albery e C.M.A. Brett,J.Electroanal.Chem., 1983, 148, 211.

[20] W.J. Albery, L.R. Svanberg e P. Wood, J. Electroanal. Chem., 1984, 162, 45.

[21] S. Bruckenstein e D.C. Johnson, Anal.Chem., 1964, 36, 2186.

Nos últimos dois anos este trabalho tem sido subsidiado pela junta Nacional de Investigação Científica e Tecnológica.

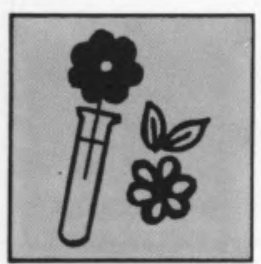

A Biotecnologia pode provocar alterações genéticas em plantas tornando-as mais resistentes à doença, o que reduzirá a necessidade de fertilizantes químicos.

G. Merritt, Time, Outubro 1989
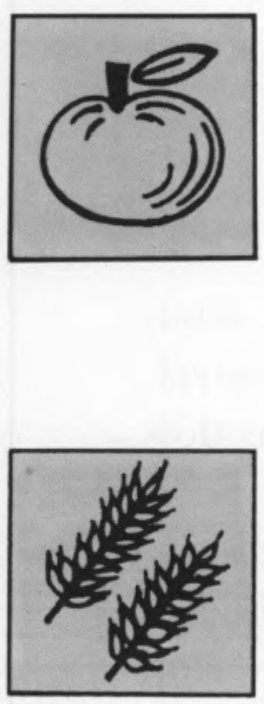

A moderna tecnologia protege e aumenta as colheitas, através do uso de insecticidas selectivos, sem prejudicar os pássaros, as abelhas e o ambiente.

Maçãs foram tratadas com "Alar", um regulador químico de crescimento. Em torno deste facto tem-se criado polémica, uma vez que um dos resíduos deste químico é um potencial cancerígeno.

E. Groth III, Science, 244, 755 (1989)

Entre os pesticidas que ingerimos, $99,99 \%$ são naturais. A maior parte dos produtos hortícolas produzem toxinas para se protegerem dos fungos, insectos e predadores como o homem. 


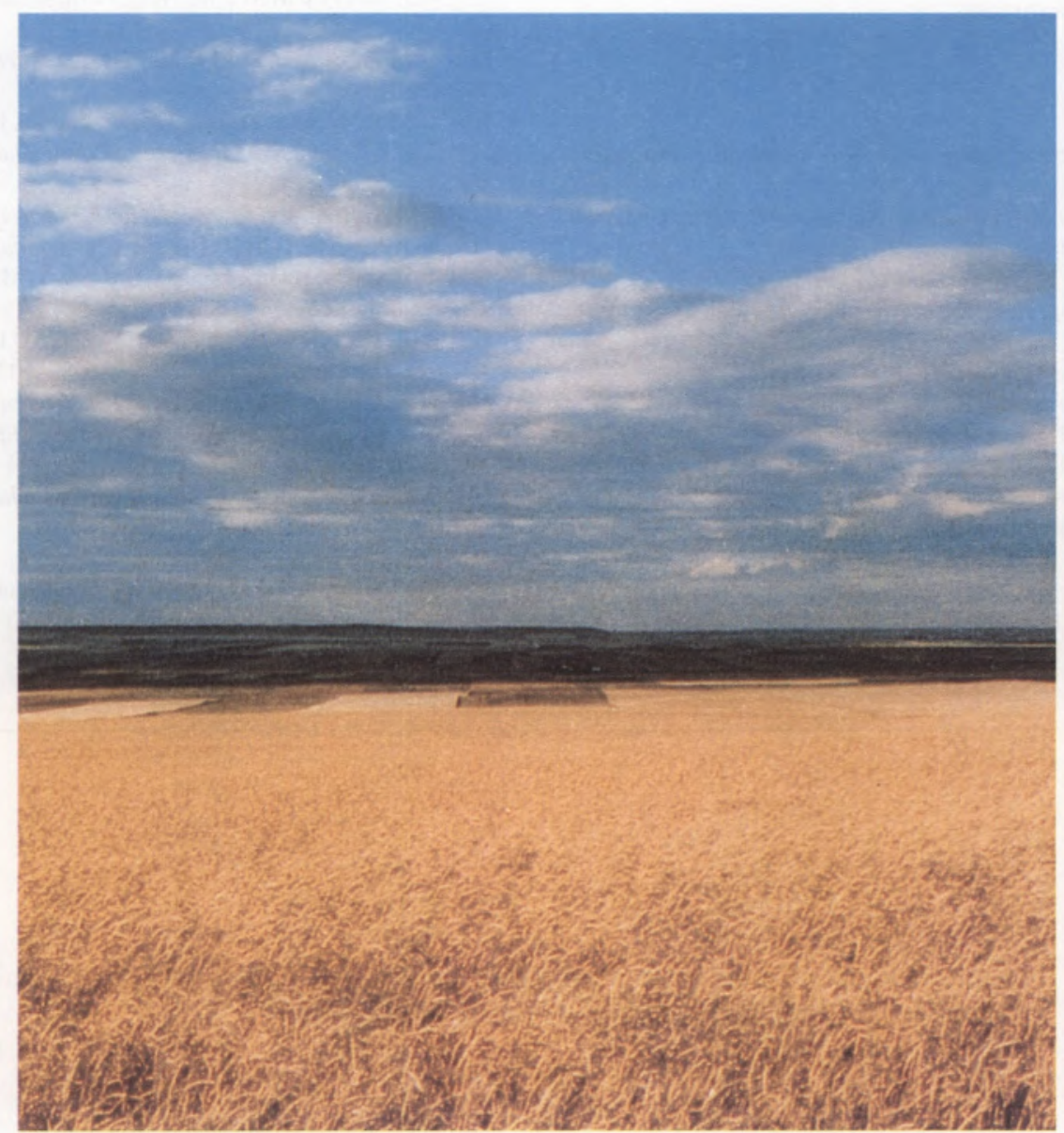

A Protecção das Plantas

O Mundo ainda pode fornecer muito alimento, apesar da população estar sempre a aumentar e da terra arável sempre a diminuir. Mas isto só é possível porque os lavradores usam produtos químicos para defender as culturas dos insectos, fungos e plantas daninhas.

Sem a protecção química às plantas, a produção de cereais na Europa decairia $1 / 4$ no primeiro ano e para quase metade no segundo. Os quentes e húmidos Inverno e Primavera da Europa, seguidos pelo Verão seco de 1989, poderiam ter originado um ano "de fome" se os agricultores não tivessem usad pesticidas. 